\title{
Intubation and extubation of patients with a heat and moisture exchanger attached to the endotracheal tube in patients with COVID-19
}

\author{
Nitu Puthenveettil, DNB (1) - Sundeep Vijayaraghavan, MCH • Sajan Rahman, MBBS • \\ Juby Mathew, MBBS
}

Received: 28 December 2020/Revised: 1 February 2021 / Accepted: 8 February 2021/Published online: 2 March 2021

(C) Canadian Anesthesiologists' Society 2021

\section{To the Editor,}

Coronavirus disease (COVID-19), transmitted mainly through droplets and aerosols, ${ }^{1}$ is highly contagious and places healthcare providers at risk of cross-infection during aerosol-generating airway procedures. ${ }^{2}$ Hence, precautions have to be taken during intubation and extubation. At our institution, the previous practice was to clamp the endotracheal tube during these procedures. During intubation, the clamp was released after the cuff was inflated and the breathing circuit connected with the heat and moisture exchanger (HME) attached to the endotracheal tube. The description by Jacob et $a l^{3}$ of the technique of clamping the tube to reduce aerosolization featured the use of a disposable plastic clamp; we used sponge-holding forceps as they are easily available in the operating room. Nevertheless, we found that clamping could damage the endotracheal tube and result in kinking during the intraoperative period, which may remain unnoticed under the drapes and result in high airway pressures. Further, a recent letter to the editor published in this Journal expressed concern regarding a risk of negative pressure pulmonary edema in patients breathing spontaneously against a clamped endotracheal tube and cautioned that aspiration of supraglottic contents caused by increased respiratory effort with an obstructed airway could increase the incidence of ventilator-associated

This submission was handled by Dr. Stephan K.W. Schwarz, Editorin-Chief, Canadian Journal of Anesthesia.

N. Puthenveettil, DNB $(\bowtie) \cdot S$. Vijayaraghavan, $\mathrm{MCH}$.

S. Rahman, MBBS - J. Mathew, MBBS

Amrita Institute of Medical Sciences, Kanayannur, Kerala, India

e-mail: nituveesundeep@gmail.com pneumonia. ${ }^{4}$ Such complications could be catastrophic in an already hypoxic patient with COVID-19.

Thus, we suggest an alternative technique to reduce the spread of COVID-19 during airway management, namely to use HMEs connected to the endotracheal tube during intubation and extubation (Figure). Heat and moisture exchangers are effective viral and bacterial filters. Our national Society of Anaesthesiologists recommends the use of two HMEs to prevent contamination of the breathing circuit and the anesthesia machine. ${ }^{5}$ This is also intended to help avoid cross-infection among patients. But instead of connecting the HME after intubation, we are now connecting it to the endotracheal tube before intubation. HMEs also can be used between the face mask and breathing circuits during preoxygenation. Following intubation, the cuff is inflated and the breathing circuit is connected to the HME.

Heat and moisture exchangers could render intubations more difficult because of their weight, which in our experience can be overcome by practice. Moreover, an assistant can support the HME to make endotracheal tube insertion easier. During extubation, we remove the endotracheal tube along with the connected HME.

We acknowledge that the use of videolaryngoscopy with deep neuromuscular blockade is recommended to improve first pass success and avoid coughing during intubation of COVID-19 patients. ${ }^{5,6}$ The use of a stylet improves the ease of intubation with videolaryngoscopes; the use of HMEs as described here precludes the use of a stylet. Nevertheless, in resource-poor countries, it is rare to have videolaryngoscopes available for all patients, and most of the intubations are performed with Macintosh laryngoscopes where the above technique can be employed. To maximize success, we also recommended 


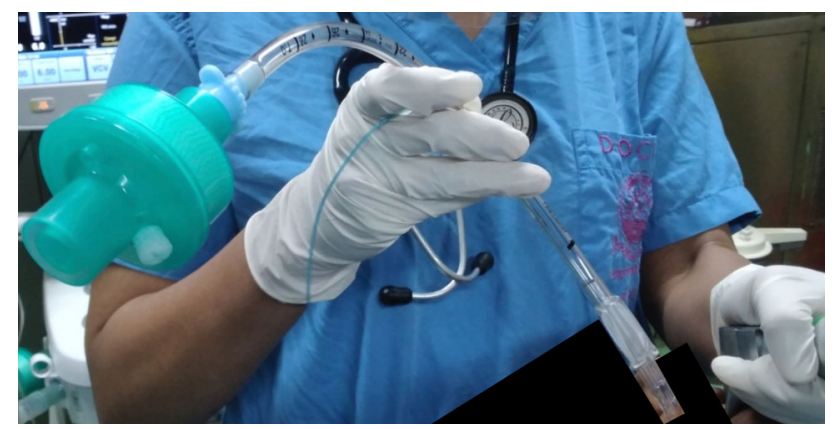

FIGURE Intubation of a patient (who consented to the publication of this image) with a heat and moisture exchanger attached to the endotracheal tube

that the senior-most available anesthesiologist perform the intubation.

Disclosures None.

\section{Funding None.}

Editorial responsibility This submission was handled by Dr. Stephan K.W. Schwarz, Editor-in-Chief, Canadian Journal of Anesthesia given in $\mathrm{ms}$, plz ck and update correct heading

\section{References}

1. Jayaweera M, Perera $H$, Gunawardana B, Manatunge $J$. Transmission of COVID-19 virus by droplets and aerosols: a critical review on the unresolved dichotomy. Environ Res 2020. DOI https://doi.org/10.1016/j.envres.2020.109819.

2. Odor PM, Neun M, Bampoe S, et al. Anaesthesia and COVID-19: infection control. Br J Anesth 2020; 125: 16-24.

3. Jacob M, Ruivo E, Portela I, et al. An innovative endotracheal tube clamp for use in COVID-19. Can J Anesth 2020; 67: 1468-70.

4. Savaie M. Does endotracheal tube clamping during intubation of COVID-19 patients increase the risk of negative pressure pulmonary edema? Can J Anesth 2020. DOI https://doi.org/10. 1007/s12630-020-01833-y.

5. Malhotra N, Joshi M, Datta R, Bajwa SJ, Mehdiratta L. Indian Society of Anaesthesiologists (ISA National) Advisory and Position Statement regarding COVID-19. Indian J Anaesth 2020; 64: 259-63.

6. Wax RS, Christian MD. Practical recommendations for critical care and anesthesiology teams caring for novel coronavirus (2019nCoV) patients. Can J Anesth 2020; 67: 568-76.

Publisher's Note Springer Nature remains neutral with regard to jurisdictional claims in published maps and institutional affiliations. 